\title{
DA HARMONIZAÇÃO DA LEGISLAÇÃO TRIBUTÁRIA ANTIEVASIVA NO MERCOSUL
}

Priscila Yumiko Sakamoto*

SUMARIO: 1. Introdução. 2. Das Formas de Aproximação legislativa e Resolução de Divergências entre Legislações (Harmonização, Coordenação e Uniformização). 3. Da Harmonização Legislativa Tributária Antievasiva e a Evasão Fiscal no MERCOSUL. 4. Conclusão. 5. Bibliografia.

SUMMARY: 1. Introduction. 2. The Legislative Forms of Approach and Resolution of Divergences Between Legislations. 3. The Legislative Tributary no Evasion Harmonization and the Fiscal Evasion in the MERCOSUL. 4. Conclusion. 5. Bibliography.

SUMARIO: 1. Introducción. 2. Las Formas Legislativas del Enfoque y la Resolución de Divergencias entre Legislaciones. 3. La Armonización de la Legislación Tributaria contraria de la Evasión y la Evasión Fiscal en el MERCOSUL. 4. Conclusion. 5. Bibliografía.

RESUMO: A harmonização tributária é um passo imprescindwel para a concreta integração do MERCOSUL, e dentro dessa aproximação das legislaçôes tributárias, é que surge a necessidade de uma norma antievasiva em comum, como importante instrumento para coibir a evasáo e diminuir a competição fiscal entre os Estados-partes.

ABSTRACT: Tax harmonization is an essential step to the concrete MERCOSUR's integration, and with this approach of tax legislations, appears a common necessity of a antievasion norm, as an important instrument to resirain evasion and to diminish fiscal competition between the State-parts.

RESUMEN: La harmonización tributaria es un paso esencial para la integración concreta del MERCOSUR, y con el acercamiento de estas legislaciones tributarias, es que surge la común necesidad de una norma

Mestranda en Direito Negocial pela Universidade Estadual de Londrina. Adrogada. E-mail: priyumikodsercomtel.com.br 
antievasiva, como instrumenta importante para refrenar la evasión y disminuir la competición fiscal entre los Estado-partes.

PALAVRAS-CHAVE: Harmonizaço tributária. Norma antievasiva. Integraço Regional. MERCOSUL.

KEY-WORDS: Tax Hamonization Antivasion Nom Rgional integtation MERCOSUR

PALABRAS-LLAVES: Hatmonización tributaria. Norma Antievasiva. Integración regional. MERCOSUR.

\section{Introdução}

Para Henry Tilbery ${ }^{1}$, um dos precursores do estudo da harmonização tributária, os agrupamentos econômicos mais importantes surgiram depois da Segunda Grande Guerra Mundial, com a finalidade de alargar as barreiras do comércio internacional.

E, a classificação que Tilbery utiliza para definir esses agrupamentos, traduzem as atuais fases da integração regional, que são: a Zona de Livre Comércio, a União Alfandegária, o Mercado Comum e finalmente a União de Tributos Internos.

Seus estudos referiam-se à extinta ALALC, no entanto, verifica-se que não é nova a idéia de que para a efetiva integração de um Mercado Comum Sul Americano, há necessidade de uma integração da legislação tributária, ao lado das integrações comercial, econômica e política.

Assim, o fato de que uma harmonização da legislação tributária também é imprescindivel para a concreta e efetiva consolidação do bloco regional é pacífica. Entretanto, é árduo o caminho que deverá ser percorrido para uma final harmonia, principalmente quando os sistemas tributários dos Estados-membros ainda guardam discrepâncias que praticamente impossibilitam tal avanço.

Neste ponto, surge a problemática da evasão fiscal entre os Estadosmembros, que pelas freqüentes fugas de capitais para países que possuem uma legislação tributária mais favorecida ao contribuinte, acabam por perder na arrecadação de milhões de dólares em tributos. Enquanto que os países que atraem esse fluxo de capitais e investimentos, nem sempre recebem em seus cofres valores de origem lícita.

$\mathrm{E}$, com base nessa contingência, é que a doutrina vem acenado para a elaboração de normas antievasivas de tributos, que se adotadas por todos os Estadosmembros do MERCOSUL, diminuiriam a competição fiscal entre os mesmos, bem como, auxiliaria o combate à evasão fiscal dentro do próprio bloco.

'TILBERY, Henry. Tributação e Integração da América Latira. Ed. José Bushatshky: Säo Paulo, 1971. p. 10-13. $\overline{392}$ 


\section{Das Formas de Aproximação legislativa e Resolução de Divergên- cias entre Legislações (Hatmonização, Coordenação e Uniformização)}

De início, cabe analisar quais as formas de aproximação legislativa possíveis de serem aplicadas para a ideal harmonização de norma antievasiva.

Em primeiro plano, o Tratado de Assunção em seu artigo 1o estabelece o compromisso dos Estados Partes de harmonizar suas legislações, nas áreas pertinentes, para lograr o fortalecimento do processo de integração.

Tal dispositivo determina a integração legislativa como uma das etapas da integração regional, e essa harmonização é interpretada neste caso, latu senso, e compreende a aproximação legislativa pela harmonização (strictu senso), e também por meio da coordenação e da uniformização, que podem ser assim definidas:

a) A harmonização (strictu senso) se traduz, portanto, em uma aproximação ou estreitamento das legislações, de modo a eliminar-lhes as divergências mais discrepantes, reduzindo as diferenças entre os ordenamentos dos Estados-partes, colocando-as em equilíbrio, de forma que se tornem harmônicas entre $\mathrm{si}^{2}$;

b) A coordenação por sua vez, implica em estabelecer estratégias comuns, onde os Estados coordenam suas normas e ações, para um determinado fim³; e

c) A uniformização, como o próprio termo já pressupõe, é a iniciativa de transformar as coisas para lhes dar uma forma igual, ou para as apresentar como idênticas, ou análogas 4 . Portanto, a uniformidade entre as legislações dos Estados-partes, pode resultar até mesmo em uma identidade textual, o que não significa que necessariamente, haverá uma unidade legislativa.

É importante ainda destacar, que essas formas não necessariamente são etapas graduais que devem ser ultrapassadas uma a uma para que se chegue à seguinte, mas sim devem ser trabalhadas em conjunto, podendo-se afirmar que atualmente, o MERCOSUL vivencia um misto da harmonização e da coordenação legislativa, que, no entanto, ainda está no início, havendo muito o que aproximar legislativamente, principalmente na área tributária.

\footnotetext{
${ }^{2}$ HARMONIZAR. [...] significa ainda por em ordem ou por em equilibrio uma coisa com a outra, de forma que não se anote qualquer discordância entre elas, quando é necessário faze-las harmônicas entre si. DE PLÁCIDO E SILVA. Op. Cit. p. 756.

${ }^{3}$ FERNANDES, Edison. Normas Tributárias do Mercosul. In. MARTINS, Ives Gandra (coord.) 0 direito tributário no mercosul. Rio de Janeiro: Forense, 2000, p. 200.

${ }^{4}$ UNIFORME. Do latim uniformis, de unus (um) e forma (forma, espécie), entende-se o que é da mesma espécie, ou se mostra de forma semelhante. É, assim, o igual, o idèntico, o análogo, o similar. [...] Não traduz propriamente, o sentido de unificar, porquanto na uniformização, embora tomem a forma igual, ou única, as coisas mantêm a individualidade, enquanto na unificação elas a perdem para formar uma unidade nova, conseqüente da reunião, ou da fusão, fundada na unificação. DE PLÁCIDO E SILVA. Vocabulário Jurídico. Forense: Rio de Janeiro - São Paulo, 1975. p. 1608.
} 
Portanto, a par das formas de aproximação, verifica-se que existem mecanismos para a resolução das divergências legislativas tributárias, mas que os Estados Partes pouco aplicaram entre si, em relação às práticas evasivas de tributos.

Ainda quanto à harmonização tributária, Ganser e Wilhem ${ }^{5}$, formularam algumas regras a serem seguidas quais sejam:

a) as legislações tributárias dos países membros devem respeitar a livre competição, a fim de não prejudicarem entre si pelos seus sistemas tributários, alíquotas de impostos ou base tributária;

b) os sistemas tributários devem ser ajustados de forma que, quando extintas as barreiras alfandegárias, não haja necessidade de substituí-las por barreiras da tributação interna; e

c) assegurar a liberdade dos Estados de fixar alíquotas para os seus impostos, de acordo com as suas necessidades financeiras, sem porém infringir as duas regras anteriores.

Todavia, a globalização do mercado internacional vem permitindo a ação desleal de alguns países, que em desrespeito à livre competição às demais regras supra mencionadas, elaboram politicas fiscais e tributárias que atraem os investidores internacionais a aplicar em seus territórios, seja por oferecer sigilo bancário, menor aliquota sobre a renda ou ainda, permitir desordenamente o estabelecimento em seu solo, das denominadas empresas off-shore, que servem em alguns casos para a lavagem de dinheiro e desvio de capitais, e que contribuem para a evasão fiscal de contribuintes dos outros Estados.

No âmbito internacional, a Organização para a Cooperação e Desenvolvimento Econômico - OCDE, vem combatendo tais condutas, além de manter e divulgar uma lista-negra dos países considerados paraísos fiscais pela comunidade internacional.

Atualmente, no MERCOSUL, a evasão fiscal é tratada internamente por cada Estado Parte, que possui sua própria legislação de coibição à sonegação ou fraude fiscal, e neste ponto é que deveria haver uma maior cooperação em relação à harmonização legislativa.

O sistema tributário brasileiro tem avançado sobre as lacunas que permitem a evasão e até mesmo a elisão fiscal, sendo estas leis denominadas de normas antielisão, o que demonstra a impropriedade óbvia, pois é a evasão nas formas de sonegação e fraude que se deve combater, sendo mais bem denominadas como normas antievasão. 
Buscando uma definição para o que vem a ser a evasão tributária, verificou-se que a doutrina é bastante divergente, ora a diferenciando ora a assemelhando à elisão fiscal, ou mesmo ao planejamento tributário ${ }^{6}$.

De maneira genérica, a maior parte da doutrina entende a evasão tributária nos termos apresentados por Maria Rita Ferragut ${ }^{7}$, consistindo em todo o ato omissivo ou comissivo, de natureza ilícita, praticado com o fim único de diminuir ou eliminar a carga tributária, ocultando o verdadeiro ato ou a real situação jurídica do contribuinte.

Dessa forma, verifica-se que o Brasil, publicou a Lei n. 8.137 de 27 de dezembro de 1990, que define como crimes contra a ordem econômica e tributária, quaisquer atos que visem suprimir ou reduzir tributo ou qualquer acessório, mediante certas condutas ou procedimentos ${ }^{8}$.

No mesmo sentido, a Lei Complementar 104 de 2001, acrescentou o parágrafo único à redação do Art. 116 do CTN, na tentativa de coibir as práticas evasivas (e também as elisivas), denominada de norma geral antielisiva que assim dispõe: a autoridade administrativa poderá desconsiderar atos ou negócios jurídicos praticados com a finalidade de dissimular a ocorrência de fato gerador ou a natureza dos elementos constitutivos da obrigação tributária, segundo procedimentos a serem estabelecidos pela lei ordinária.

Sem adentrar ao mérito da constitucionalidade ou não de norma geral tributária, no ordenamento jurídico brasileiro, cabe mencionar também que a Argentina, por seu turno, baseia o seu modelo tributário em cláusula geral de elusión fiscal, disposta na Lei n. ${ }^{\text {a }} 11683$, que no artigo 46 dispõe: El que mediante declaraciones engañosas o ocultación maliciosa perjudicare al Fisco com liquidaciones de impuestos que no correspondan a realidad, será reprimido con multa de dos (2) hasta diez (10) veces el importe del tributo evadido.

\footnotetext{
"GRECO, Marco Aurélio. Planejamento Fiscal e Interpretação da Lei Tributária. Dialética: São Paulo, 1988. p.43. ${ }^{7}$ FERRAGUT, Maria Rita. Evasão Fiscal: o Parágrafo Único do artigo 116 do CTN e os Limites de sua Aplicação. Revista Dialética de Direito Tributário. № 67. Abr/2001.

"Dentre os quais pode-se mencionar: a) Omitir informação, ou prestar declaração falsa às autoridades fazendárias; b) Fraudar a fiscalização tributária inserindo elementos inexatos, ou omitindo operação de qualquer natureza, em documento ou livro exigido pela lei fiscal; c) Falsificar ou alterar nota fiscal, fatura, duplicata, nota de venda; d) Elaborar, distribuir, fornecer, emitir ou atualizar documento que saiba ou deva saber falso ou inexato; e) Negar ou deixar de fornecer, quando obrigatória, nota fiscal ou documento equivalente, relativa à venda de mercadoria ou prestação de serviço efetivamente realizada, ou fornecê-la em desacordo com a legislação, caracteriza a mesma infração a falta de atendimento da exigência da autoridade, no prazo de dez dias, que pode ser convertido em horas em razão da maior ou menor complexidade da matéria ou da dificuldade quanto ao atendimento da exigência; f) Fazer declaração falsa ou omitir declaração sobre rendas, bens ou fatos, ou empregar outra fraude, para eximir-se, total ou parcialmente, de pagamento de tributos; g) Deixar de recolher, no prazo legal, valor de tributo descontado ou cobrado, na qualidade de sujeito passivo de obrigação e que deveria recolher aos cofres públicos. Entre outros procedimentos.
} 
Contudo, dentre os Estados membros do MERCOSUL, os maiores esforços legislativos no combate à evasão fiscal partem dos dois paises supra-mencionados, não havendo ainda acordo de aplicação regional relativo à matéria.

O Uruguai, peculiarmente, oferece uma legislação tributária com menos encargos e portanto, atrai fluxo de capital estrangeiro de países do bloco, e também de terceiros, que buscam um maior rendimento de seus investimentos, ou uma menor tributação e controle sobre a sua renda, em decorrência do sigilo bancário?.

No entanto, apesar da política fiscal privilegiada, não é considerado pela comunidade internacional ${ }^{10}$, como um paraíso fiscal propriamente dito, mas sim, conforme a classificação lecionada por Heleno Taveira Torres ${ }^{11}$, é um país com regime tributário favorecido, classificado como low tax system.

Contudo, esse posicionamento fiscal é prejudicial quando se assegura o sigilo de contas ilícitas, e dá oportunidade para a lavagem de dinheiro, sonegação e fraude, abrigando práticas evasivas apenas possíveis em sistemas tributários mais favoráveis.

Assim, conforme as regras da harmonização de Ganser e Wilhem, no MERCOSUL ainda há que se fazer cumprir a primeira delas, que é coibir a competição fiscal que direta ou indiretamente conduza à evasão de tributos.

\section{Conclusão}

Desta feita, a harmonização da legislação tributária é sem dúvida uma das etapas mais dificeis a ser ultrapassada na integração regional do MERCOSUL, assim como foi para a União Européia, uma vez que são diferentes Estados, com diferentes legislaçốes, e necessidades e interesses arrecadatórios divergentes entre si.

Entretanto, deve haver uma maior preocupação com as práticas evasivas que ocorrem entre os Estados do próprio bloco econômico, uma vez que essa verdadeira lacuna legislativa que existe em desfavor da integração regional fomenta a concorrência fiscal desleal, e que, somado à quase ausência de cooperação entre o Estados membros em relação à harmonização de norma tributária antievasiva, torna-se um entrave aos fins almejados pelo bloco econômico como um todo.

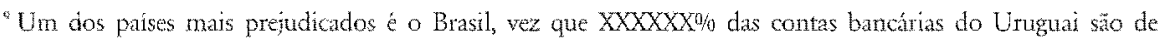
titulares brasilemos. $O$ fato em si, näo quer necessariamente dizer que a origem das contas é ilicita, entretanto, muitos sonegadores e fradadores do fisco utilizam-se do sigilo oferecido pelo sistema bancírio uriguaio. ${ }^{10}$ Nào integra a black list da OODE, nem a lista negra da Secretaria da Receita Federal do Brasil, por noro se enquadrar nos criterios utilizados para a elaboraçăo das listas, que levatn en conta as aliquotas do inposto sobre a tenda.

"Tôrres afirma que existem três tipos de modelos de paises con regime de tributação favorecida: i) os low tax system, onde as aliquotas são inferiores, mas não são fortemente preiudiciais a outros sistemas; ii) os preferential tax system, onde as aliquotas säo muito reduzidas ou nulas; e ii) os tax heavens, ou paraisos fiscais. O Uruguai, teoticamente, enquadra-se na primérra hipótese, vez que apenas mantém una aliquota inferor de tributaçăo à reoda. TORRES. Heleno Taveira. Diteito Trbutáno Intenacional: Planejamento tributh́rio e operações transnacionais. RT: São Paulo, 2001. p. 70-71.
} 
Em suma, é urgente a necessidade de desenvolver mais ações a fim de intercambiar informações tributárias entre os Estados Partes, para o mútuo auxílio no combate à competição tributária internacional, o que poderia ser solucionado mediante reformas das constituições internas e de acordos de harmonização legislativa tributária, objetivando primordialmente a integração regional, resguardados, todavia, os limites insuperáveis do ordenamento jurídico interno, como as cláusulas pétreas que abrigam os princípios da legalidade, da tipicidade e da liberdade econômica no Brasil.

Porém, a questão envolve mais vontade e interesses políticos e econômicos, do que necessariamente esforço legislativo.

\section{BIBLIOGRAFIA}

AMARAL, Gilberto Luiz. A Lei Complementar 104/2001 e o Planejamento Tributário. IBPT. Disponível no endereço eletrônico <http:// www.tributarista.org.br>, Acesso em: 26/05/01.

DE PLÁCIDO E SILVA. Vocabulário Jurídico. Forense: Rio de Janeiro - São Paulo, 1975.

FABRETTI, Láudio Camargo. Normas Antielisão. IBPT. Disponível no endereço eletrônico: <http://www.tributarista.org.br/content/estudos/antielisao.html> Acesso em: 19/06/01.

FERNANDES, Edison. Normas Tributárias do Mercosul. In. MARTINS, Ives Gandra (coord.) O direito tributário no mercosul. Rio de Janeiro: Forense, 2000.

FERRAGUT, Maria Rita. Evasão Fiscal: o Parágrafo Único do artigo 116 do CTN e os Limites de sua Aplicação. Revista Dialética de Direito Tributário. № 67. Abr/2001.

GRECO, Marco Aurélio. Planejamento Fiscal e Interpretação da Lei Tributária. Dialética: São Paulo, 1988.

GUIMARÃES, Renato Prado. O Uruguai e o Mercosul. Disponível no endereço eletrônico: <http://www.mre.gov.br/unir/webunir/BILA/16/1artigo/ 2prado.htm>. Acesso em: 25/09/01.

HUCK, Hermes Marcelo. Evasão e Elisão Rotas Nacionais e Internacionais do Planejamento Tributário. Saraiva. São Paulo, 1997.

KOBE, Ana Carolina de Almeida. KOBE, Ana Paula de Almeida. Uruguai: Paraíso Fiscal do Mercosul?. Direito da integração e relações internacionais: ALCA, MERCOSUL e UE. p. 53 a 57. Org. Otávio Pimentel. Fundação Boiteux. Florianópolis, 2001.

LIPPERT, George Neto. A Harmonização Tributária do MERCOSUL. Dissertação. Universidade de São Paulo. São Paulo, 1998.

MARTINS, Gilberto de Andrade. Elaboração de Artigo para Publicação em Periódico. Disponível no endereço <http://www.eac.fea.usp.br/metodologia/ artigo.asp> Acesso em 02/08/03. 
MARTINS, Tves Gandra (coord), O direito tributário no mercosul. Rio de Janeiro: Forense, 2000.

MENDONÇA, Oscar. Artigo da Lei contra a Elisão Fiscal. Disponível no endereço eletrônico: 〈http:/www.jus.com.br/doutrina/lc104.html〉. Acesso em: 07/06/2001.

NÓBREGA, Mailson da. O futuro incerto da lei contra a elisão fiscal. $O$ Estado de São Paulo. São Paulo, 21 de janeiro de 2001. Disponível no endereço eletrônico: 〈http://www.estadao.com.br/agestado〉. Acesso em: 24/07/ 2000.

OECD. Report to the 2000 Ministerial Council Meeting and Recommendations by the Committee on Fiscal Affairs. Progress in Identifying and Eliminating Harmful Tax Practices. - Disponível no endereço eletrônico: 〈http:/www.oecd.org/daf/fa/harm_tax/Report_En.pdfs. Acesso em: 25/09/01.

PORTO, Ricardo Philippi. Os Princípios Tributários e a Harmonização Fiscal no MERCOSUL. Dissertação. Mestrado em Direito da Universidade Federal de Santa Catarina. Florianópolis, 2001.

TAMER, Sérgio. Unicidade Tributária. in Revista Jurídica Consulex. Brasília: Ano II, n. 24 , p. 40, dez/1998.

TILBERY, Henry. Tributação e Integração da América Latina. Ed. José Bushatshky: São Paulo, 1971.

TÔRRES, Heleno Taveira. Direito Tributário Internacional: Planejamento tributário e operaçôes transnacionais. RT: São Paulo, 2001.

XAVIER, Alberto. Tipicidade da Tributação, Simulação e Norma Antielisiva. Dialética: São Paulo, 2001. 